\title{
A Review of Various Strategies for Contrail Avoidance
}

\author{
Klaus Gierens ${ }^{*}$, a Ling Lim $^{\mathrm{b}}$ and Kostas Eleftheratos ${ }^{\mathrm{c}}$ \\ ${ }^{a}$ Institute of Atmospheric Physics, DLR Oberpfaffenhofen, Germany \\ ${ }^{b}$ Centre for Air Transport and the Environment, Manchester Metropolitan University, UK \\ ${ }^{c}$ Laboratory of Climatology and Atmospheric Environment, University of Athens, Greece
}

\begin{abstract}
A review is given of various contrail avoidance strategies that have been developed since the publication of the Intergovernmental Panel on Climate Change (IPCC) special report on Aviation and the Global Atmosphere. The goal of this review is to provide an overview of the various options for contrail mitigation, to describe the state of the art, and to indicate future directions for research.
\end{abstract}

Keywords: Aviation, climate, contrails, cirrus, mitigation.

\section{INTRODUCTION}

Aircraft, like every other powered vehicle, emit a number of species into the atmosphere that lead to changes in atmospheric composition and may have major or minor effects on the climate. The aviation case is, however, special in two respects. First, much of the emissions occur in the tropopause region where atmospheric residence times are much longer than near the ground. Second, aircraft emissions can give rise to anthropogenic clouds, termed condensation trails (or contrails) that under appropriate atmospheric conditions can spread out and eventually cover large areas in the upper troposphere. Since contrails consist of ice, the resulting clouds are termed contrail cirrus. A recent review of contrail formation and properties and of contrail climate effects can be found in Schumann [1].

The IPCC special report on Aviation and the Global Atmosphere [2] attributed the second largest climate effect (in terms of radiative forcing, $\mathrm{RF}^{1}$ ) of aviation specific emissions to linear contrails (in 1992; for the $2050 \mathrm{Fa}$ scenario, contrails have the largest RF). The contribution of contrail cirrus was estimated to be even larger, but considered so uncertain that it was excluded from the final estimate of total aviation forcing. Since then, more recent research has indicated a considerably smaller RF from linear contrails [3]. Nevertheless, the estimate of contrail cirrus RF, while still uncertain, remains the largest of all estimates.

Demand for air transport is expected to increase at a rate of about 5\% per annum over the next 20 years [4], this suggests a significant increase in fractional coverage of linear contrails $[5,6]$. A consequential increase in the coverage and frequency of occurrence of contrail cirrus and therefore their climate impact may therefore be expected as well. These

*Address correspondence to this author at the Institute of Atmospheric Physics, DLR Oberpfaffenhofen, Germany; E-mail: Klaus.Gierens@dlr.de

1 $(\mathrm{RF})$ Radiative forcing is a measure of the importance of a potential climate change mechanism. It expresses the perturbation or change to the energy balance of the Earth-atmosphere system in Watts per square meter $\left(\mathrm{W} / \mathrm{m}^{2}\right)$. Positive values of radiative forcing imply a net warming, while negative values imply cooling [2] considerations have led researchers, climate scientists and aircraft engineers alike, to develop strategies for avoiding contrail formation or mitigating the problem in order to reduce the impact of air traffic emissions on global warming. The goal of this review is to provide an overview of the various possibilities for contrail avoidance, to describe the state of the art, and to indicate future directions for research.

In Section 2 we provide a short description of contrails and contrail cirrus in the atmosphere, and their potential climatic effects. In the remainder of the review we discuss potential contrail mitigation options, both technical (Section 3) and operational (Section 4). A summary is given and conclusions are drawn in Section 5.

\section{CONTRAILS AND CONTRAIL CIRRUS IN THE ATMOSPHERE, AND THEIR POTENTIAL CLI- MATIC EFFECTS}

Condensation trails (contrails) are aircraft induced cirrus clouds, which may persist and grow to form large cirrus cover in ice-supersaturated air, thereby causing a warming of the atmosphere [1].

A contrail is a visible line cloud, consisting of tiny ice particles, that forms behind an aircraft if the ambient air is cold enough [7]. In dry air, contrails dissolve quickly and their impact is of minor importance, but in moist air which is super-saturated with respect to ice, contrails grow with the uptake of ambient water vapour, spread, and become contrail-cirrus [1].

A contrail-cirrus cloud is a naturally looking cirrus cloud that would not exist without prior formation of a contrail [8]. This type of cirrus formation occurs mainly in regions with high levels of air traffic (i.e., North America, North Atlantic, and Europe).

Recent studies [9-16] have shown evidence of increasing trends in cirrus/high cloud coverage over congested air traffic regions which may be attributed to aviation activities. Major findings of those studies are summarised in [8]. Over central Europe, aircraft induced cirrus coverage is estimated to have increased by about $1-2 \%$ per decade. The coverage by additional cirrus clouds is estimated to be about $3 \%$ 
which is about ten times higher than the coverage by linear contrails $(\sim 0.3 \%)$ alone. However, the estimation of that ratio is fraught with severe difficulties. Recently Mannstein and Schumann [17] noted: "that the coverage by additional cirrus clouds is in Europe about 10 times higher than by linear contrails (Mannstein and Schumann, 2005) can no longer be supported. Further work is needed to discriminate between contrail cirrus and natural cirrus. The factor may turn out to be significantly lower than $10 . "$

As air traffic increases ( $\sim 5 \%$ per year), manmade (aviation) cirrus clouds are expected to increase. These additional clouds contribute to the greenhouse effect. Using as a metric of climate change the concept of radiative forcing (RF), the new estimate of total RF from aviation for the year 2000 (48 $\mathrm{mW} / \mathrm{m}^{2}$ ) is about the same as that of IPCC (1999) for the year 1992 [3]. The new estimate does not include a contribution from aviation-induced cirrus clouds. The RF of contrailcirrus depends not only on the additional coverage, but also on their geographic location, altitude, time of day and year, and the background state of the atmosphere (e.g. whether there are lower clouds or not). High-altitude thin contrail cirrus tends to warm the Earth-Atmosphere system during day and night time, if located above a bright and warm surface, while low-altitude thick contrail cirrus tends to cool the Earth-Atmosphere system during day time especially if located above dark and cold surfaces.

Present knowledge of the coverage and RF of manmade cirrus clouds is still poor. However, it is conceivable that these cirrus clouds could be responsible for up to a doubling of the present estimate of aviation RF. If this is true, then the contribution of aviation to total anthropogenic RF (which is $\sim 3.5 \%$ for 1992 aircraft operations [2]) could be doubled.

Particulate emissions from aviation may also trigger cloud formation and alter cloud properties even when no persistent contrails are involved. If aviation aerosol is found to contain relatively efficient ice nuclei, such particles could lead to ice crystal formation prior to natural formation of cirrus, but a long time and a large distance away from the original time and place of emission. Such an indirect effect could in principle work whether or not a short-lived contrail is involved, but the involvement of a short-lived contrail could enhance the effect because of preactivation. Preactivation means that tiny amounts of ice remain in the cracks and pores of soot particles after evaporation of the contrail [18]. These tiny ice remainders can act as good ice nuclei in the later fate of the particles. There are indications of the existence of such indirect effects, but so far, they have not been confirmed. Ström and Ohlsson [19] found "absorbing material" (most probably soot) in cirrus ice crystals during research flights in southern Germany. The occurrence of this material was particularly strong in the cruise altitudes of air traffic. Ice crystal number densities in regions with absorbing material were factors of $1.6-2.8$ higher than in regions without absorbing material, and the crystals were smaller with absorbing material than without [20]. Such microphysical changes generally lead to changes in the flow of radiative energy through the atmosphere; hence they cause a radiative forcing. However, the indirect effects, if they exist at all, are so poorly understood, that not even an estimate of their radiative forcing exists. At present it is not possible to give any mitigation suggestion for this potential problem, but one should be aware that this problem might well exist.

\section{CONTRAIL FORMATION AND PHYSICS OF YOUNG CONTRAILS: TECHNICAL MITIGATION OPTIONS}

\subsection{Contrail Formation and the Schmidt-Appleman Cri- terion}

Contrail formation is determined almost exclusively by principles of thermodynamics and the atmospheric conditions in which engine emissions are released. The theory of contrail formation, known as the Schmidt-Appleman criterion, can be described by a simple equation containing atmospheric temperature and pressure, specific fuel energy content, specific emission of water vapour and the so-called overall propulsion efficiency. The Schmidt-Appleman criterion states that a contrail forms if, during the plume expansion process, the mixture of exhaust gases and ambient air transiently achieves saturation with respect to liquid water. The fact that the mixture must reach approximately water saturation (and not only ice saturation or any other relative humidity) is the only empirical component of the SchmidtAppleman theory, and it is the only part that is related to the ice-forming properties of emitted particles. It simply means that the emitted particles are only poor ice forming nuclei and act as cloud condensation nuclei, i.e. they first trigger the formation of liquid droplets that freeze afterwards. The validity of the Schmidt-Appleman theory has been demonstrated and confirmed on various research flights [2, 21-23]. This validation also proves that thermodynamics is the controlling factor for contrail formation, not the physicochemistry of the emitted particles. An excellent derivation of the Schmidt-Appleman theory has been given by [7].

The mixing process is assumed to take place isobarically, so that on a $T$-e diagram the mixing (phase) trajectory appears as a straight line ( $e$ is the partial pressure of water vapour in the mixture, $T$ is its absolute temperature, see Fig. (1)). The slope of the phase trajectory, $G$ (units $\mathrm{Pa} / \mathrm{K}$ ), is characteristic for the respective atmospheric situation and aircraft/engine/fuel combination. $G$ is given by

$$
G=\frac{E I_{H 2 O} p c_{p}}{\varepsilon Q(1-\eta)}
$$

where $\varepsilon$ is the ratio of molar masses of water and dry air (0.622), $c_{p}=1004 \mathrm{~J} /(\mathrm{kg} \mathrm{K})$ is the isobaric heat capacity of air, and $p$ is ambient air pressure. $G$ depends on fuel characteristics (emission index of water vapour, $E I_{H 2 O}=1.25 \mathrm{~kg}$ per kg kerosene burnt; chemical heat content of the fuel, $Q=$ $43 \mathrm{MJ}$ per $\mathrm{kg}$ of kerosene), and on the overall propulsion efficiency $\eta$ of aircraft. Modern airliners have a propulsion efficiency $(\eta)$ of approximately 0.35 .

The Schmidt-Appleman criterion only determines whether a contrail will form or not. It does not account for contrail persistency or whether a contrail can spread out into extended contrail cirrus. Persistency is only possible if the ambient air is supersaturated with respect to ice, which means that once ice crystals are formed in the plume they can grow until either the air becomes eventually subsaturated or until the ice crystals fall (due to their weight) into lower 
subsaturated atmospheric layers where they will then evaporate.

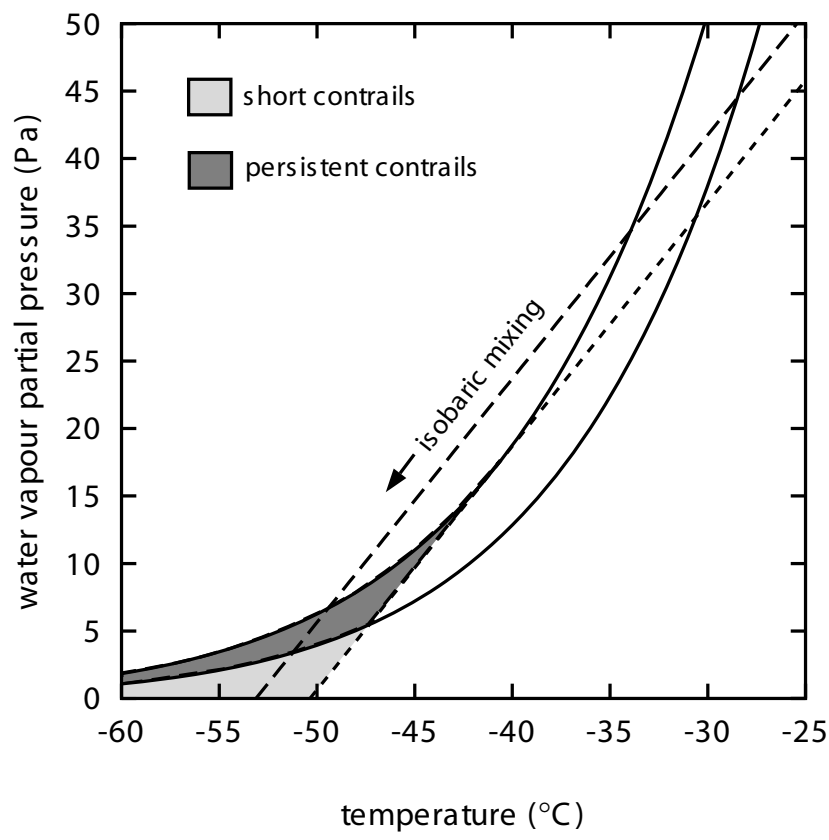

Fig. (1). Sketch of the Schmidt-Appleman criterion. The two solid curves represent saturation with respect to liquid water (upper curve) and with respect to ice (lower curve). The phase trajectory of the mixture of exhaust gases and the ambient air is a straight line (from upper right to lower left) in the $e-T$ diagram (dashed). The trajectory tangent to the water saturation curve (dotted) marks the warmest temperatures for which contrail formation is possible. Contrails are persistent and can spread out into contrail cirrus when the trajectory ends in an ice supersaturated state. Otherwise, the contrail will be short with a life time of up to a few minutes.

\subsection{Technical Options for Suppressing Contrails}

The thermodynamic control of contrail formation has a consequence for technical contrail mitigation options: it is not possible to alter contrail formation conditions by changing the character of the emitted particles (soot, sulphuric acid solution droplets, particulate organic matter) or particle precursor gases $\left(\mathrm{SO}_{2}, \mathrm{SO}_{3}\right)$. A change of these emissions leads to changes in contrail composition and properties (e.g. particle number and size, contrail optical thickness, etc.), but not in formation conditions.

Technical mitigation options for contrails can only include those that lead to a decrease in the water vapour emission index, $E I_{H 2 O}$, or lead to an increase in the specific heat content of the fuel, $Q$, or lead to a decrease of the overall propulsion efficiency, $\eta$.

The use of alternative fuels could be an option for reducing contrails because they involved changes in $E I_{H 2 O}$ and $Q$. Out of several potential fuels, the IPCC report on aviation [2] considers only cryogenic liquid hydrogen (LH2) and methane as viable alternatives (in the long term) because other liquid fuels (ethanol, methanol) have energy densities that are too low. However, neither hydrogen nor methane fuels would serve to reduce contrail formation because both have larger ratio $E I_{H 2 O} / Q$ than kerosene. This so-called en- ergy-specific emission index is $0.045 \mathrm{~kg} / \mathrm{MJ}$ for methane, and $0.075 \mathrm{~kg} / \mathrm{MJ}$ for $\mathrm{LH} 2$, while it is $0.029 \mathrm{~kg} / \mathrm{MJ}$ for kerosene ([2], table 7-11). Assuming equal $\eta$, the $G$ factor of an LH2 engine is 2.6 times higher than that of a kerosene engine, for methane the factor is 1.55 . Hence, aircraft flying on these alternative fuels could potentially produce contrails at even higher ambient temperatures (hence at lower altitudes) than kerosene-driven aircraft.

Fuel additives would leave the factor $G$ unaffected (otherwise it would not be termed an additive), but could make the condensation potential of emitted particles so low (for instance through hydrophobic coating of particles) that a higher supersaturation would be necessary for contrail formation. According to the Schmidt-Appleman theory such an effect can be incorporated by replacing $G$ by $G / x$ where $x$ is the saturation ratio needed for contrail formation (the normal kerosene contrail has $x=1$ ). Gierens [24] has shown, by reanalysing a number of flight experiments using kerosene of varying sulphur content, that it is extremely difficult to drive $x$ even slightly (for example 0.04 ) beyond its standard value of unity. However, merely to balance the expected increase in overall propulsion efficiency (up to $\eta=0.5$ in 2050) would require an increase of $x$ to about 1.4. Gierens [24] therefore concluded that fuel additives are not a viable contrail mitigation option.

An overview on technology options to reduce contrails and contrail cirrus has been given by Noppel and Singh [25]. Recently, a novel engine concept has been proposed that would serve as a contrail suppression strategy via a reduction of the emission index for water vapour $[26,27]$. Much of the water vapour would instead be either emitted or stored internally in the liquid state. The novel concept is based on the intercooled and recuperated engine cycle. The idea is to cool the exhaust air with an additional heat exchange unit (cooled by bypass air) such that water vapour can condense in the unit. In this way the emission index of water vapour can be substantially reduced which helps to suppress contrails. The condensed water can be stored or poured away in the form of precipitating water drops or ice crystals. The condensation of water can serve two additional purposes: First the emitted aerosol particles (mainly soot) can be scavenged in the condensation process, and second, part of the condensed water can be reinjected into the combustion chamber in order to reduce $\mathrm{NO}_{\mathrm{x}}$ production. The cycle calculations indicate that the new concept allows higher thermal efficiencies than conventional designs to cut back greenhouse gas emissions. However, significant advances in heat exchanger technology are required to make this concept feasible.

Haglind [28] has investigated how technical measures that would change the overall propulsion efficiency would work in a contrail reduction scenario. The idea is that such measures would be applied temporarily when the aircraft flies through regions where persistent contrails are likely to form. Haglind [28] found that by employing variable guide vanes for the fan of an engine, $\eta$ (hence $G$ ) could be changed such that the threshold temperature for contrail formation would drop by about $1.5 \mathrm{~K}$. A typical atmospheric temperature lapse rate of, for example, $4.5 \mathrm{~K} / \mathrm{km}$ would correspond to a vertical distance of $300 \mathrm{~m}$, or approximately $1000 \mathrm{ft}$. During periods of lowered $\eta$, the specific fuel consumption (SFC) rises by $42-48 \%$ depending on altitude as a direct con- 
sequence of the inverse proportional relationship between SFC and $\eta$. Hence, in order to keep the price of such a contrail mitigation strategy low, such a method would have to be combined with operational measures as discussed below.

It would appear therefore that while technical solutions to contrail avoidance are not currently available, it is still possible to change contrail optical and microphysical properties in a way that makes them less detrimental for the climate.

\subsection{Changing Contrail Properties}

If it turns out that technical contrail suppression is ineffective, not feasible, inhibited for safety reasons, or too expensive, it is still possible to investigate ways to alter contrail optical and microphysical properties such that their detrimental effects upon the environment are reduced. This then becomes more a question of the properties of the exhaust aerosol than a matter of thermodynamics which gives rise to a variety of new potential solutions. It might even be possible to achieve an overall environmental gain by such an approach when, as in the case of LH2 driven aircraft (so-called cryoplanes) the thermodynamic constraints for contrail formation weaken, rendering contrail formation possible at lower flight levels. An example of how this could work is provided by the case of the cryoplane.

Since no aerosol is formed by burning LH2, cryoplane contrails are believed to form only on aerosol particles mixed in from the ambient air [7]. Additionally, there is the possibility that an LH2 engine emits aerosol particles, because the engine will take in and burn ambient aerosol, and new particles may form in the cooling exit section of the engine [29]. But even then, cryoplane contrails are predicted to consist of 1-2 orders of magnitude less ice crystals than contrails from equivalent kerosene fuelled engines [30]. Since contrail ice mass is controlled by ambient humidity, ice crystals in cryoplane contrails are 4-6 times larger (linear dimension) than those in kerosene contrails. The larger size favours earlier fallout of the crystals and it makes cryoplane contrails optically thinner than their kerosene counterparts by an average factor of three [30]. Admittedly, these results are based on numerical simulations only since in-flight measurements of cryoplane contrails do not exist.

It seems that both effects, the larger volume of the atmosphere where cryoplane contrails can form and the smaller optical thickness compared to conventional contrails, nearly balance in terms of climate radiative forcing [31]. However, the most recent assessment [32] concludes that the effect of the smaller optical thickness dominates over the higher frequency of cryoplane contrails, so there is potential for an environmental benefit through the introduction of LH2 technology, if the LH2 can be produced from renewable energy sources.

The inertia of the climate system and the severe technical requirements for the introduction of a cryoplane fleet are large, so that the benefits of LH2 technology will probably only appear in a timescale of 50 or more years [32].

There has been some work on fuel additives suitable for reducing particulate emissions from aircraft. Liscinsky et al. [33] compared the particulate production from burning JP-8 (a kerosene derivative) and JP- $8+100$. The mass of the emitted particles was estimated to be $60-70 \%$ less than with unal- tered JP-8. In addition, the number density, mean diameter and smoke number showed reductions as well. However, the authors noted large experimental uncertainties. Other experiments with JP8 and a number of additives have been undertaken $[34,35]$, but they did not report such a large effect as [33] for JP-8+100. In any case, even a $60-70 \%$ reduction of particulate number density would not have a large effect on contrail properties like crystal number concentration and optical thickness $[22,36]$, since only a small fraction of all particles (less than one percent) end up in contrail ice crystals. Hence the number of particulates must be reduced substantially (by orders of magnitude of $\sim 2$ ) to reduce the number density of contrail ice crystals. Less ice crystals would imply lower optical thickness [37], bigger individual crystals (since the water mass condensing on the ice is unaffected), and therefore larger fall velocities; i.e. this type of contrail is from the beginning, optically thinner than contrails of conventional kerosene fuel, and it will dissipate quicker by sedimentation of the ice crystals into lower atmospheric layers.

\subsection{Aerodynamic Contrail Formation}

Another class of contrails that is independent of the Schmidt-Appleman criterion and also independent of the exhaust properties is aerodynamically induced contrails. This type of contrails has been detected in photographs taken from the cockpit of another aircraft nearby. Seemingly these contrails are rarely observed, but quick calculation shows that the flow over a wing of an aircraft should in general (due to the Bernoulli effect and adiabatic cooling) get cold enough at cruise altitudes to turn even relatively dry ambient air into a supersaturated state [38]. It is likely that the time for condensation, freezing, and ice crystal growth is often too short to render a visible effect. However, in future aircraft designs involving a blended wing-body structure or flying wings, this may no longer be a constraining factor since the average wing depth will then increase substantially compared to the current fleet. Furthermore, such contrails will probably occupy warmer (but ice supersaturated) regions than the usual exhaust contrails. Thus they can form in a much larger part of the troposphere than exhaust contrails. It is not clear so far, whether they could be avoided by appropriate airfoil profiles without a deterioration to uplift. This would suggest that the most effective approach would be to devise operational contrail mitigation options as are considered next.

\section{OPERATIONAL MITIGATION OPTIONS}

A potential operational mitigation option to reduce contrail formation is to change flight altitudes. Sausen et al. [39] presented a contrail climatology for 1992 aviation and compared it to hypothetical cases where total air traffic is displaced up and down by one kilometre. The results showed that mid-latitude contrails are suppressed by flying higher (because more flights occur in the dry stratosphere), while in the tropics it is necessary to fly at lower altitudes in order to avoid contrails (because there it is too warm for contrail formation). One option for contrail reduction in the midlatitudes is thus to fly slightly higher, namely in the extratropical lowermost stratosphere which is generally too dry for contrail persistence [1]. Tradeoffs of such a strategy 
(such as longer residence times of emitted species in the stratosphere and chemical impacts upon ozone) first need to be analysed.

Flying at lower altitudes can also lead to contrail reduction in the mid-latitudes, however severe constraints on the highest permissible flight level would have to be imposed in order to achieve a substantial effect (e.g. maximum flight level of $10000 \mathrm{ft}$, about $3000 \mathrm{~m}$, in winter time), in particular when the North American and North Atlantic air space is considered [40, 41]. Such severe air space restrictions generally imply adverse consequences for total fuel burn (since aircraft have to operate at non-optimal altitudes, with higher levels of air drag) and journey times; additionally the number of conflicts (aircraft coming too close to each other) would rise, leading to a substantial increase in work load of air traffic controllers [40]. Flying lower also implies that more time is spent in turbulent air with consequential adverse effects on passenger comfort and, more importantly, with increased loads on aircraft structures [42]. These undesirable side effects of hard flight level constraints led Williams et al. [43] to conclude that more flexible constraints that take into account the actual atmospheric situation are needed.

Fichter et al. [44] conducted a parametric study to determine potential responses of the climate system to changes in flight altitudes. Simulating contrails in a global climate model, they showed that by downshifting the cruise altitude by $2000 \mathrm{ft}, 4000 \mathrm{ft}$ and $6000 \mathrm{ft}$, the global annual mean contrail coverage was reduced in an approximately linear manner, up to a maximum decrease of $\sim 45 \%$ for a $6000 \mathrm{ft}$ lower cruise altitude. The global mean radiative forcing by contrails was reduced almost proportionally to the contrail coverage. This study also showed that the changes in contrail coverage and radiative forcing due to altitude changes have a strong seasonal and regional variability, as demonstrated in Fig. (2). Adaptation to latitudinal, seasonal, and ideally to short-term changes in ambient parameters was considered a better strategy for contrail avoidance than global displacements of flight levels. Rädel and Shine [45] investigated the effect of flight level changes on global radiative forcing by taking the AERO2k inventory and increasing the air traffic in $2000 \mathrm{ft}$ thick layers by $10 \%$. Increasing the air traffic on levels between 10 and $12 \mathrm{~km}$ altitude increases radiative forcing more than increasing the traffic in both higher and lower levels. From this study it seems that shifting the air traffic away from the most sensitive layers to either higher or lower levels would reduce the radiative impact from contrails.

Changing flight altitudes systematically requires redesigning of aircraft to optimally operate in the new levels. Reducing flight levels generally leads to increase in fuel consumption, an effect that seems to be smaller for cryoplanes than for conventional planes due to different fuel storage configurations [46].

Mannstein et al. [47] found that relatively small changes in flight level can avoid a substantial fraction of contrails and contrail induced cirrus, due to the shallowness of the ice supersaturation layers (which are the regions where contrails persist and spread into contrail-cirrus). A prerequisite for a strategy to avoid ice supersaturated regions is the ability of aviation weather forecasts to predict the location of such regions. Currently, only very few weather forecast models address ice supersaturation, a situation that must be improved. New developments in the capability of meteorological models, such as the ECMWF (European Centre for Medium-Range Weather Forecasts) operational model, to predict ice supersaturated regions [48] means that it may be possible in the near future to predict whether persistent contrails can form in a specific region at a specific time. Equipping a number of commercial airliners with humidity probes that are designed especially for use in the upper troposphere (including AMDAR, Aircraft Meteorological Data Reporting to the weather centres) would help aviation weather forecasts to more accurately predict ice supersaturated regions.

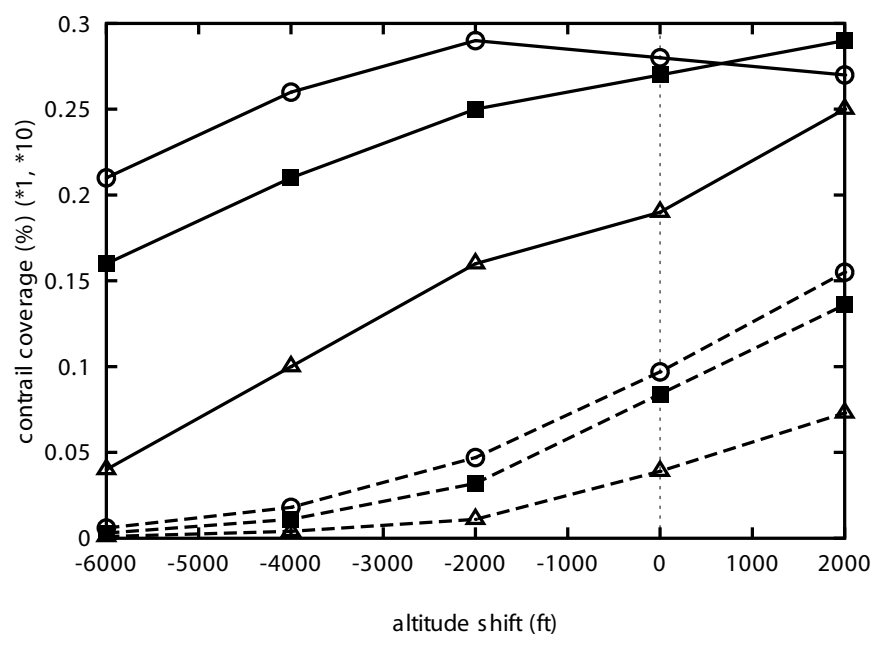

Fig. (2). Contrail coverage $v s$ constant altitude shifts of air traffic. Solid lines refer to the North Atlantic flight corridor, broken lines to the tropics. Note that tropical contrail coverage is multiplied by a factor of 10 for ease of reading the figure. Solid squares are annual means, open circles are January means, and open triangles are July means. Data provided by Christine Fichter, DLR.

In addition to reducing contrail formation, there is also a potential operational mitigation option for reducing the climate impacts from contrails. Meerkötter et al. [49] found that "contrails cool the surface during the day and heat the surface during the night", with the resulting net effect that is highly dependent on the daily variation of contrail coverage. Whereas the longwave (terrestrial) radiative forcing varies only little over the day, the shortwave (solar) forcing displays a strong diurnal cycle due to the variation of the sun's position (zenith angle). Hence, it has been suggested that "altering the time for aircraft traffic has the potential for reducing the radiative forcing due to contrails" [50]. In a case study [50] it has been shown that "assuming a limited persistence of contrails, any shift in the traffic density towards sunrise and sunset would reduce the RF due to contrails".

The results from [51] suggest that most of the RF from contrails can be attributed to night-time flights. Even though only $25 \%$ of aircraft movements occur at night, they account for $60-80 \%$ of the contrails' RF. For the situation in southeast England, flights in the evening hours (18-24 GMT) turned out to have the largest net radiative forcing, in particular in winter. In fact, although $22 \%$ of annual air traffic movements are winter flights, they contribute about half of the annual mean RF from contrails. Therefore, rescheduling 
flight times to daylight hours could minimize the climate impact from contrails [51].

A strategy, designed to achieve environmentally optimum flight routings (avoiding ice supersaturated air masses) especially for flights in the evening and night hours, is now being investigated as part of the German climate protection programme (http://www.pa.op.dlr.de/ufo/). As air traffic density is lower during the night, when contrails have a large individual radiative forcing, there is a greater opportunity for redirecting flights out of ice supersaturated regions without dramatically enhancing the work load of air traffic controllers. The adoption of such routing only for aircraft producing the "worst" contrails would help make such a strategy affordable and keep fuel consumption penalties to a minimum.

Klima [52] developed a contrail modelling tool to investigate the cost of operational contrail mitigation options. Surprisingly, she found that it was possible to substantially reduce the number of persistent contrails by rerouting aircraft (by $65-80 \%$ ) and simultaneously achieve an average decrease of $5-7 \%$ in the total operating cost for the studied example. Klima [52] states that the cost reduction reflects non-optimal routing of the actual flights with respect to fuel burn and operating costs. Whether such a gain is indeed possible is, however, currently unclear because the study suffers from a number of uncertainties. Most seriously, the study did not take into account air traffic control constraints. Other uncertainties included, for instance, the model assumptions, too coarse air traffic data, and the special weather situation that pertained during the study period.

The potential approaches to reducing contrails are likely to have consequences for other effects, e.g. through $\mathrm{NO}_{\mathrm{x}}-\mathrm{O}_{3}$ formation or increased fuel burn, resulting in increased $\mathrm{CO}_{2}$ emissions. In an initial study Grewe et al. [53] found that if overall cruise altitudes were reduced, then $\mathrm{NO}_{\mathrm{x}}$ emissions increased - however, less $\mathrm{O}_{3}$ was formed because of increased rates of chemical removal and washout of $\mathrm{NO}_{\mathrm{y}}$ species. Likewise Fichter [44] found that the 6,000 ft reduction in overall cruise altitudes resulted in an increase in $\mathrm{CO}_{2}$ emissions of $6 \%$. The increase in RF from $\mathrm{CO}_{2}$ was not calculated as this would require assumptions over timing of changes and the full effect would not be observed for some time. Since this was a parametric study, such a calculation was deliberately not undertaken as it could have been interpreted, misleadingly, as a 'scenario'.

\section{SUMMARY AND CONCLUSIONS}

Contrail cirrus has the potential to significantly increase aviation's share of global warming. In view of the large predicted increase of demand for air transport, measures should be taken to either avoid or suppress contrail formation or to change their properties such that they would become optically thinner and have shorter lifetime (by higher sedimentation rates of the ice crystals). In this review we have presented some potential mitigation options, both technical and operational. From the technical viewpoint we have seen that it is difficult to avoid contrail formation since this is mainly controlled by thermodynamics. New engine cycles and technical facilities that have the potential for contrail suppression have been proposed. In addition to contrail suppression measures to lower the number of particles emitted can also be considered. This would not lead to contrail avoidance, but to optically thinner contrails with less and therefore heavier ice crystals. These would obtain higher fall speeds, possibly leading to on average, shorter contrail lifetimes.

Operational mitigation options have been discussed as well. Hard options (i.e. fixed constraints such as maximum allowed flight levels) seem to be impractical because of the severe additional work load on air traffic controllers and consequential safety problems. Instead, research nowadays favours flexible operational measures that take the actual weather situation into account. Currently, the quality of scientific knowledge on the radiative forcing of contrails and contrail cirrus still spans the range from fair to very poor [3]. While the RF of linear (i.e. young) contrails can be computed with a fair degree of confidence, the integrated RF of a contrail during its complete life-time has never been calculated. More research is also required on the linkage between persistent contrails and contrail cirrus. The global mean coverage and climate impact of contrail cirrus is still unknown. Hence it appears premature at the current state of knowledge to propose any single operational mitigation strategy. However, research on the potential impacts, benefits and tradeoffs of various mitigation options should be conducted simultaneously to enhance scientific knowledge on contrails, contrail cirrus, and their radiative forcing. Progress is also required in aviation weather forecasting: their models must be able to predict ice supersaturated regions for any viable operational mitigation option. One example is the Integrated Forecast Model of the European Centre for Medium-Range Weather Forecasts [48], which has included ice supersaturation as an explicit feature since Sept. 2006. This new feature will lead to better forecasts for aviation weather, which in turn can be used to develop environmentally compatible flight routings. Such a possibility would also avoid the aerodynamically induced contrails that might otherwise become more prominent with the advent of blended wing-body aircraft and flying wings.

\section{ACKNOWLEDGEMENTS}

This review is an extended version of a report provided to the European FP6 Network of Excellence ECATS (Environmentally Compatible Air Transport System). The authors would like to thank Frank Noppel for checking the interpretation of his results and Fredrik Haglind for providing access to his results prior to publication. Ulrich Schumann, Bernd Kärcher, and David Lee provided valuable comments to a first version of the manuscript. Ian Waitz made us aware of Kelly Klima's thesis. Thanks also to Christine Fichter for providing the data for Fig. (2). Finally, we thank Callum Thomas for improving the language.

\section{REFERENCES}

[1] Schumann U. Formation, properties and climatic effects of contrails. C R Phys 2005; 6: 549-65.

[2] Penner JE, Lister DH, Griggs DJ, Dokken DJ, McFarland M. Aviation and the Global Atmosphere. IPCC. Cambridge University Press 1999.

[3] Sausen R, Isaksen I, Grewe V, et al. Aviation radiative forcing in 2000: An update of IPCC (1999). Meteorol Z 2005; 14: 555-61.

[4] Rogers HL, Lee DS, Raper DW, Forster PM de F, Wilson CW, Newton PJ. The impacts of aviation on the atmosphere. Aeronaut J 2002; 106: 521-46. 
[5] Gierens K, Sausen R, Schumann U. A diagnostic study of the global distribution of contrails. Part II. Future traffic scenarios. Theor Appl Climatol 1999; 63: 1-9.

[6] Marquart S, Ponater M, Mager F, Sausen R. Future development of contrail cover, optical depth and radiative forcing: Impacts of increasing air traffic and climate change. J Climate 2003; 16: 28902904.

[7] Schumann U. On conditions for contrail formation from aircraft exhausts. Meteorol Z 1996; 5: 4-23.

[8] Gierens K. Contrails, contrail cirrus, and ship tracks. International Conference on Transport, Atmosphere and Climate, Oxford, UK, June 2006.

[9] Boucher O. Air traffic may increase cirrus cloudiness. Nature 1999; 397: 30-31.

[10] Minnis P, Ayers JK, Palikonda R, Doelling DR, Schumann U, Gierens K. Changes in cirrus cloudiness and their relationship to contrails. Proceedings American Meteorology Society. Boston, USA 2001; No. 11.9: pp. 239-42.

[11] Minnis P, Ayers JK, Palikonda R, Phan D. Contrails, Cirrus Trends, and Climate. J Climate 2004; 17: 1671-85.

[12] Zerefos CS, Eleftheratos K, Balis DS, Zanis P, Tselioudis G, Meleti C. Evidence of impact of aviation on cirrus cloud formation. Atmos Chem Phys 2003; 3: 1633-44.

[13] Stubenrauch CJ, Schumann U. Impact of air traffic on cirrus coverage. Geophys Res Lett 2005; 32: L14813.

[14] Stordal F, Myhre G, Stordal EJG, et al. Is there a trend in cirrus cloud cover due to aircraft traffic? Atmos Chem Phys 2005; 5: 2155-62.

[15] Mannstein H, Schumann U. Aircraft induced contrail cirrus over Europe. Meteorol Z 2005; 14: 549-54.

[16] Krebs W. Analyse des Einflusses des Flugverkehrs auf die natürliche Zirrusbewölkung über Europa, Nordafrika und dem Nordatlantik. Ludwig-Maximilians Universität München. 2006; pp. 211 (in German).

[17] Mannstein H, Schumann U. Corrigendum to "Aircraft induced contrail cirrus over Europe". Meteorol Z 2007; 16: 131-32.

[18] Suzanne J, Ferry D, Popovitcheva O, Shonija NK. Ice nucleation by kerosene soot under upper tropospheric conditions. Can J Phys 2003; 81: 423-29.

[19] Ström J, Ohlsson S. In situ measurements of enhanced crystal number densities in cirrus clouds caused by aircraft exhaust. J Geophys Res 1998; 103: 11355-361.

[20] Kristensson A, Gayet JF, Ström J, Auriol F. In situ observations of a reduction in effective crystal diameter in cirrus clouds near flight corridors. Geophys Res Lett 2000; 27: 681-84.

[21] Busen R, Schumann U. Visible contrail formation from fuels with different sulfur contents. Geophys Res Lett 1995; 22: 1357-60.

[22] Kärcher B, Busen R, Petzold A, Schröder FP, Schumann U, Jensen EJ. Physicochemistry of aircraft-generated liquid aerosols, soot, and ice particles. 2. Comparison with observations and sensitivity studies. J Geophys Res 1998; 103: 17129-48.

[23] Jensen EJ, Toon OB, Kinne S, et al. Environmental conditions required for contrail formation and persistence. J Geophys Res 1998; 103: 3929-36.

[24] Gierens K. Are fuel additives a viable contrail mitigation option?. Atmos Environ 2007; 41(21): 4548-52.

[25] Noppel F, Singh R. An overview on contrail and cirrus cloud avoidance technology. J Aircraft 2007; 44: 1721-26.

[26] Noppel F, Singh R, Taylor M. Novel engine concept to suppress contrail and cirrus cloud formation. International Conference on Transport, Atmosphere and Climate, Oxford, UK, June 2006.

[27] Taylor MD, Noppel FG, Singh R. A gas turbine engine. EP1852590, Nov. 2007

[28] Haglind F. Potential of lowering the contrail formation of aircraft exhausts by engine re-design. Aerosp Sci Technol 2008; in press.

[29] Chen JP. Particle nucleation by recondensation in combustion exhausts. Geophys Res Lett 1999; 26: 2403-06.

[30] Ström L, Gierens K. First simulations of cryoplane contrails. J Geophys Res 2002; 107, doi:10.1029/2001JD000838.
[31] Marquart S, Ponater M, Ström L, Gierens K. An upgraded estimate of the radiative forcing of cryoplane contrails. Meteorol Z 2005; 14: 573-82.

[32] Ponater M, Pechtl S, Sausen R, Schumann U, Hüttig G. Potential of the cryoplane technology to reduce aircraft climate impact: A stateof-the-art assessment. Atmos Environ 2006; 40: 6928-44.

[33] Liscinsky DS, Colket MB, Hautman DJ, True B. Effect of fue additives on particle formation in gas turbine combustors. AIAA paper 2001-3745. AIAA/ASME/SAE/ASEE Joint Propulsion Conference and Exhibit, 37th, Salt Lake City, UT, July 8-11, 2001.

[34] Bae JH, Avedisian CT. Effect of TPGME blending on soot emissions from JP8 fuel droplets burning with spherical symmetry. AIAA paper 2004-5680. 2nd International Energy Conversion Engineering Conference, Providence, Rhode Island, Aug. 16-19, 2004.

[35] Montgomery CJ, Sarofim AF, Preciado I, Marsh ND, Eddings EG, Bozzelli JW. Experimental and numerical investigation of sootreducing fuel additives. AIAA paper 2005-4472. 41st AIAA/ ASME/SAE/ASEE Joint Propulsion Conference and Exhibit, Tucson, Arizona, July 10-13, 2005.

[36] Kärcher B, Yu F, Schröder FP, Turco RP. Ultrafine aerosol particles in aircraft plumes: analysis of growth mechanisms. Geophys Res Lett 1998; 25: 2793-96.

[37] Liou KN. Radiation and Cloud Processes in the Atmosphere. Theory, Observation and Modeling. Oxford University Press, New York, Oxford, 1992.

[38] Gierens K, Kärcher B, Mannstein H, Mayer B. Aerodynamically induced formation of contrails. International Conference on Transport, Atmosphere and Climate, Oxford, UK, June 2006.

[39] Sausen R, Gierens K, Ponater M, Schumann U. A diagnostic study of the global distribution of contrails, Part I. Present day climate. Theor Appl Climatol 1998; 61: 127-41.

[40] Williams V, Noland RB, Toumi R. Reducing the climate change impacts of aviation by restricting cruise altitudes. Transp Res Part D 2002; 7: 451-64.

[41] Williams V, Noland RB, Toumi R. Air transport cruise altitude restrictions to minimize contrail formation. Clim Policy 2003; 3 : 207-19.

[42] Green JE. Civil aviation and the environmental challenge. Aeronautical J 2003; 107: 281-99.

[43] Williams V, Noland RB. Variability of contrail formation conditions and the implications for policies to reduce the climate impacts of aviation. Transp Res Part D 2005; 10(4): 269-80.

[44] Fichter C, Marquart S, Sausen R, Lee DS. The impact of cruise altitude on contrails and related radiative forcing. Meteorol Z 2005; 14(4): 563-72.

[45] Rädel G, Shine K. Radiative forcing by persistent contrails and its dependence on cruise altitudes. J Geophys Res 2008; in press.

[46] Svensson F, Hasselrot A, Moldanova J. Reduced environmental impact by lowered cruise altitude for liquid hydrogen-fuelled aircraft. Aerosp Sci Technol 2004; 8: 307-20.

[47] Mannstein H, Spichtinger P, Gierens K. A note on how to avoid contrail cirrus. Transp Res Part D 2005; 10: 421-26.

[48] Tompkins AM, Gierens K, Rädel G. Ice supersaturation in the ECMWF integrated forecast system. Q J Roy Meteor Soc 2007; 133: 53-63.

[49] Meerkötter R, Schumann U, Doelling DR, Minnis P, Nakajima T, Tsushima Y. Radiative forcing of contrails. Ann Geophys 1999; 17: 1080-94.

[50] Myhre G, Stordal F. On the tradeoff of the solar and thermal infrared radiative impact of contrails. Geophys Res Lett 2001; 28(16): 3119-22.

[51] Stuber N, Forster P, Rädel G, Shine K. The importance of the diurnal and annual cycle of air traffic for contrail radiative forcing. Nature 2006; 441: 864-67.

[52] Klima K. Assessment of a global contrail modeling method and operational strategies for contrail mitigation. MIT 2005; pp. 172.

[53] Grewe V, Dameris M, Fichter C, Lee DS. Impact of aircraft NOx emissions. Part 2: effects of lowering the flight altitude. Meteorol Z 2002; 11: 197-205 